Journal of Education and Vocational Research

Vol. 4, No. 10, pp. 311-316, Oct 2013 (ISSN 2221-2590)

\title{
Polytechnics as Institutions for Intraregional Collaboration for Skills Development in Africa
}

\author{
${ }^{*}$ Kutsanedzie F., Achio S., Mensah, E. \\ Accra Polytechnic Research \& Innovation Department, Accra, Ghana \\ *kingkut11@yahoo.co.uk
}

\begin{abstract}
The Polytechnics in Ghana were established and given the mandate enshrined in the Constitution of Ghana under the Act of Parliament of the Republic of Ghana (Act 745) to train students in the fields of Science, Technology, Applied Social Science and Applied Art to serve the middle-manpower management needs of the country. In addition, the polytechnics are to provide skills development, conduct and publish industry driven research findings. Polytechnic graduate are expected by employers and captains of industry to be more practical-skilled and biased by virtue of their training. However, over the years, it appears the polytechnic graduate training is becoming more of theoretical rather than what was initially intended. Commentaries of stakeholders reveal that the polytechnics are gradually losing their focus vis-à-vis the practical training of students as they are fast comparing themselves to the universities. This paper uses observation of the polytechnics educational system, interviews with stakeholders and other secondary data as the bases to critically examine and identify the conditions that hamper the practical training of the polytechnic students practical content of syllabi; teacher - student ratio in the face of high student intake; qualification of lecturers in terms of practical training. It thus recommends ways by which the polytechnics can improve upon the practical training of its student via mobilizing and utilizing its resources to create industries to facilitate the training of its students as well as reducing graduate unemployment. This thus will serve as lynch-pin to drive the country's industrialization process.
\end{abstract}

Keywords: Polytechnics; practical training; educational system; industry; programmes, course content

\section{Introduction}

Background: Polytechnics are tertiary institutions that have been set up to train students in the Technical and Vocational Education and Training (TVET) areas. The core mandate of the polytechnics according to Ghana Legal (2013) as dictated by the Polytechnics Acts 745 of Ghana 2007 is teaching of students, and the second conducting applied research - aimed at facilitating the industrialization of the country. From the inception of the Polytechnic, it was envisaged that it would serve as a centre for training students to serve the middle-manpower management needs of the country. According to Ayogyam et al. (2012), there is a current development in Ghana where students graduating from the tertiary institutions find it difficult to secure employment and this has become extremely worrisome. Employers have complained over the years that, though students are knowledgeable, they lack practical skills hence they become less useful to industry. The syllabi of the programmes run in the polytechnics are expected to be practical biased or oriented to equip students with the needed practical know-how that is aimed at distinguishing them from their colleagues trained in analogous institutions like the universities in the same programmes. However, over the years, polytechnics have churned out graduates for the World of Work with no distinctive straits of skills that distinguishes them from other trained graduate apart from the certificates issued to them. It suggests that the practical mode of training the polytechnic graduate have not been effective, and thus the need to re-examine the systems of training critically and recommend ways of addressing this gap. According to Dr. Ephraim Avea Nsoh, Upper West Regional Minister in Ghana indicated in a delivered speech that Polytechnics in Ghana have completely lost the purpose for which they were established. He stated that they have shifted their focus on the training of students, who use only their minds at the work place (Ghana Business News, 2013). In addition, many commentators, employers and captains of industries have made categorical statements to the effect that the polytechnics have lost their focus and vision for which they have been established and are training graduates just like the universities. This paper examines critically polytechnic education in Ghana, and recommends ways to aid the student acquire the requisite practical know-how that would make them distinctive in the world of work. It also aimed at making recommendations which will help facilitate the 
industrialization process of the country as well as using the polytechnics as industry incubation centres for the country.

Research Questions: The study poses the following questions:

- Can polytechnic graduates be identified in the world of work by the practical skills they exhibit on the job rather than their certification?

- How effectively can the polytechnic graduate be trained to attain distinctive practical traits?

- Are the Polytechnics engaging practically competent lecturers D. Tech and M. Tech holders in their quest of running technology degrees?

- Do the polytechnics have adequate facilities to equip students with the needed practical skills in the face of increasing enrolments and high student- teacher ratio?

- Can the polytechnics together serve as industrial incubation centres for training of students with the needed practical skills as well as creating jobs for their graduates to facilitate the industrialization process of the country?

Problem Statement: Polytechnic trained graduates are expected by virtue of their training to be more practical oriented or biased as compared to their colleagues trained in the universities. They are to serve the middle-level manpower management needs of the country in the drive towards industrialization. Although the polytechnics have been churning out graduates into the World of Work over since their establishment, this pertinent role is becoming illusive because there seems to be no distinctive practical traits exhibited by the polytechnic graduates that distinguish them from the university trained graduates. There is a need to examine the system to identify the gaps created and recommend ways to achieve their mandate of producing practical-biased graduates to aid the country's industrialization process or agenda.

Objectives of the Study: The main aim of this paper is to critically examine the training of the polytechnic students in the light of identifying gaps that exist in the training process that makes it unable for the graduates to acquire adequate practical skills that would make them distinguishable from graduates trained by analogous tertiary institutions such as the universities; make constructive recommendations geared towards equipping polytechnic trained graduates with the requisite practical skills; as well as using the polytechnics as centres industry hubs in the country to facilitate the drive to industrialization, leading consequently to graduate employment.

Justification of Study: The polytechnic since its inception was mandated to train students who are to serve the middle-level manpower management needs of the country. Over the years, the polytechnic has churned out a large number of graduates who are in World of Work. Oftentimes, in most jobs requirements advertised in both the print and electronic media, whenever there are vacant positions opened up for both holders of bachelor degree and Higher National Diploma (HND) certificates, holders of the latter certificate are expected to garner more work experience than the former. This presupposes that the polytechnic graduates have less practical skills as compared to their colleagues trained in the universities. Meanwhile polytechnic graduate by their training, are expected to more practical inclined than their colleagues trained in the universities. But the case in point clearly suggests employers; captains of industries in their quest to employ graduates disregard practical training background of the polytechnic graduate. Employers are gradually realizing that the polytechnics are training their students more theoretical and so the value expected to be placed practical skills is gradually being eroded. The essence of education is not only knowledge acquisition but the translation of the knowledge acquired into solving problems that pose threat to ones society and the world at large. Parents are not only concerned about the grades their wards obtained when they complete tertiary institution, but rather whether the can be employed; employees would prefer caliber of graduates who have the relevant practical skills and hence needs little or no training at all in order to save money on training; the tertiary institutions are most happy if their graduates occupy high positions and jobs as well as becomes employers; governments sees graduates partnering it to solve age-long problem of unemployment of its citizenry when they turn to create jobs using their acquired knowledge and skills; lastly the graduates are happier when they secure jobs than scoring the best of grades. Findings from this study when implemented would be beneficial to all stakeholders and especially the polytechnics in the realization of the mandate for their establishment. 


\section{Methodology}

The study is an exploratory research that seeks to look at the deficits in the polytechnic educational system that make it difficult to equip the polytechnic graduates with the needed practical expected to make them distinctive in World of Work, using Accra Polytechnic in Ghana as a case study. It therefore employed the use of observation of the polytechnic training system; review of secondary data such as press cuttings of news papers for employment opportunities open to Polytechnic graduates and requirements for such opportunities, course syllabi, etc.; interviewing of Heads of Academic Departments in the Polytechnic. The information from the both the primary and secondary sources as stated was reviewed and analysed to assess the practical training of the students currently, and suggestions subsequently made regarding improving the existing situations.

\section{Current Situation of Practical Training Students in the Polytechnics}

Programmes run in Accra Polytechnic: Accra Polytechnic trains students in engineering - mechanical, electrical, civil, building technology, furniture design; applied sciences - Catering, laboratory technology, computer science, fashion design, statistics; business and management studies - accounting, marketing, secretaryship and management, purchasing studies. Students who pursue programmes and complete successfully are awarded Higher National Diploma, while some students also further in other few programmes for the award of Bachelor of Technology (Accra Polytechnic Matriculation Brochure, 2012). However, apart from the programmes in the engineering and some programmes in the applied sciences such as catering and hotel management, laboratory technology and computer science, and also secretaryship and management situated in the school of business and management studies, all the other programmes do not have any practical components in the courses that constitute the programmes. The polytechnic today trains more students in management and commerce as compared to the technical and vocational areas. The current statistics in Accra Polytechnic indicate the approximate a ratio of management and commerce to technical and vocational students trained annually is 60:40 (Accra Polytechnic Annual Statistical Report, 2012; NCTE, 2012). The programmes in commerce and management are run with more inclination towards theoretical training as done by other analogous institutions such as the universities.

Practical Content of Courses on Programmes Basis: The National Accreditation Board (NAB) is the authority that gives approval for the running of tertiary courses in Ghana. The Board scrutinizes the syllabi and all other facilities needed for the running of the programmes frequently to accredit new programmes and re-accredit old programmes. The course content of all the courses run in the polytechnic were checked for their practical and theoretical content and was ascertained that those areas that fall outside the TVET areas were theoretically biased. The syllabi for programmes in the technical, vocational and technology areas reveal that some of the courses have no practical components while others have. Syllabi of courses that have practical components have indicated in them the specified number of contact hours required per student per week to acquire practical skills. Though the syllabi stated the number of hours of contact for training, interview with some of the heads of department reveal that they are unable to make the required number of hours of practical contacts per week with students because of the limited facilities in terms of equipment, and other times unavailability of consumables for practical work. Some lecturers complained that some of the practical components are very extensive and cannot be handled completely within the stipulated time, and thus aspects of the syllabi as regard the practical training needed to be reviewed to meet current trends. Observation of the course content of programmes in the TVET areas reveal that when the lecturers follow the syllabus thoroughly and religiously, students are likely to gain some expected practical skills. Meanwhile, the limitation in terms of facilities and the class size or students number do not allow the adequate hands on training of the students.

Lecturers Competency as regard their Qualifications: Currently, the requirement for lectureship positions in polytechnics in Ghana is $\mathrm{PhD}$. However, one is first taken for the position of an assistant lecturer with a master degree and required to progress to a lecturer after serving for two years after providing a satisfactory service as stated in Polytechnics Scheme of Service (2009). Also, advertisement of vacant lectureship and assistant lecturer positions in reviewed press cuttings reveal that all polytechnics require applications from $\mathrm{PhD}$, MPhil and MSc holders. Since the polytechnics are currently running progression programmes for their 
graduate in Bachelor of Technology degrees (B.Tech), and envisaging running in the near future Master of Technology degrees (M. Tech) and Doctor of Technology degrees (D.Tech), one would expect them to employ persons with D.Tech and M.Tech qualifications to fill lectureship and assistant lectureship positions respectively because they are better placed in terms of their practical training to teach in the Polytechnics. However, this is not to suggest that the other qualification cannot do same. The possible reason might be unavailability of trained personnel with these Technology degrees. However if more of these persons are recruited into the polytechnics, there will immense benefit from their practical competency in advancing the course of training students in various degrees of technology since some lecturers are likely not to conduct some practical lessons as required by the course syllabus because they are handicap in such areas.

Facilities available: The Polytechnics over the years have increased their enrolment in order to admit Senior High School Leavers. However, the infrastructural development has not seen the same level of development to accommodate this increase in enrolment. Also, the facilities such as equipment and teaching aids are inadequate to allow the students to acquire the necessary practical skills through hands-on training. This development has led to lecturers only conducting students through only few practical lessons in courses. As a result, courses that practical skills are needed for understanding are taught purely on theoretical basis due to the unavailability of laboratories and equipment. In cases where the equipment are available, the student number vis-à-vis the equipment does not permit them to have achieve the contact or exposure as stipulated by the course syllabi. These often leads to most of the technical, vocational and technology areas been trained theoretically rather than the practically. According to Stuliff (2000), industrial exposure gives the academics a chance to seek inputs and feedback from practicing professionals who can provide valuable insight into the skills and abilities students would need in their career. Ballinger and Lalwani (2000) also indicated that it offers an opportunity for students to personally practice the theoretical models in the classroom to enhance their chances of securing employment after graduation.

Proposed Model for the Training of the Polytechnic Graduate to acquire Practical Traits Distinctive from other Tertiary Trained Graduates: After a thorough observation of the Polytechnic education system, examination of secondary data and interaction with heads of departments of Accra Polytechnic on issues of practical training of students, the paper proposes that the following models be adopted to help polytechnic students acquire unique practical straits that will make them distinguishable and employable in the world of work from their colleague graduates from the universities.

Redesigning of the Conduct of Student Industrial Attachment: Many authors have confirmed that industrial attachment help to equip students not only with the necessary practical skills but also help them realize what happens in the real job situation. Most employers are of the view that not all the practical skills learnt in the school training environment are needed in the industry; hence the need for industrial training is not only for learning or acquiring practical skills but also to acquire the relevant skills needed by employers in the job market. Accra Polytechnic has introduced a compulsory industrial attachment scheme or model which is aimed at bridging the gap between theory and practice. Under the scheme, students from the Polytechnic are attached to various companies to serve on attachment during their long vacation (a period of almost three months), where lecturers are made to visit and monitor students on attachment. However, often times there are mismatch of students to the companies as marketing students find themselves in engineering firms and engineering students vice versa. Again, students in most cases are not exposed to understand what they are taught during the attachment simply because there are no outcomes or objectives provided to the industry as to skills the students are expected to gain at the end of the attachment. It thus makes students unable to link what skills acquired to their studies. Aside this, some companies add students to their workforce to augment their production capacity as a way of training of students. To make industrial attachment effective, and a complement to practical skills acquisition by student, all lecturers are to be made to outline objectives to be achieved by their students on their industrial attachment so that the industries train them accordingly. In this wise, lecturers would have the opportunity to be assisted by the industries to train students to obtain practical skills in areas that they lack facilities for or competencies are challenged in.

Using the Polytechnics to Create Industries for Student Training and Graduate Employment: There are ten polytechnics in Ghana running HND and B. Tech programmes in various disciplines such engineering, applied sciences, social sciences, management and commerce. They produce graduate each year to compete in 
the World of Work for job opportunities. Since the polytechnics are expected to give more practical approach to the training of its students, there is therefore the need to come up with more innovative and creative ways of ensuring that its graduates acquire distinctive practical skills that would distinguish them from their colleagues trained in other analogous tertiary institutions such as the universities. This paper therefore suggests that each of the polytechnics in Ghana assess its strength vis-à-vis comparative advantage to identify, solicit funding from funding agency and the government, and subsequently create an industry. These polytechnic created industries are expected to be man by graduate churned out of the polytechnics under the guidance of their lecturers to compete with other similar industries created by the private sector. When these industries are seen to be operational and able to stand the competition in the industry, it would serve as a proof for employers to know the skills exhibited by the trained graduates. When models of industries created by the polytechnics are dotted all over the country, it would not only serve as industries to accommodate students on attachment, but also create employment for numerous graduates.

With the creation of these industries, there are bound to be equipment found in there which are likely to be lacked by in the Polytechnics. Lecturers can conduct their students on filed visits to familiarize and have hands on some of this equipment, thus helping to bridge the gap between practice and theory. Taking for instance Accra Polytechnic establishing a printing industry to be managed and operated by it trained graduate. Proposal for funding can be sought from donor agencies and the government of Ghana to put up the infrastructure for the printing industry. When it comes to the developing of the site and the construction of the firms, the services of the civil engineering and building technology graduates and their lecturer can be sought; when it can to the furnishing of the infrastructure, the services of the carpentry and furniture design graduates; the computer science graduates services, can be employed in programming the computer systems; electrical and mechanical engineering graduates, to help repair and maintain these equipment; marketing graduate, for the marketing of the product; accounting graduates, for financial management of the industry; the secretaryship and management graduates, take care of typing, typesetting and management of the industry. With these setup, when employers realize that these industries managed by the Polytechnics graduate are withstanding competition and are being run successfully, the industries would come to the realization of the distinctive skills of the polytechnic graduates to allow them to be 'poached' by employers. When these modeled industries are replicated by all the polytechnics in Ghana, they would not only serve as excellent centres of training, but also industrial incubation hub for country.

Employing and training existing lecturers to acquire Technology Degrees (D. Tech, M. Tech): Polytechnics are expected to train students with a practical focus. There is a need for the Polytechnics to start looking at recruiting lecturers who have obtained technology as well as training existing lecturers to acquire technology degrees, since they envisage training their students for progression in higher technology degrees such as $\mathrm{M}$. Teach and D. Teach. Currently, the persons with D. Tech and M. Teach are few and unavailable. It is expected that the polytechnics marshal resources to train it lecturers in these technology degrees to have more practical oriented staff. The recruiting and training of persons with these technology degrees might not help solving the practical needs of the polytechnic but may go a long way to uniquely ensure that there is practically biased staff ready for the training of students for the technology degrees.

Recommendation: It is recommended that in the attempt of Polytechnics creating the model industry, they do not veer off their track by going solely into commercial ventures while neglecting their core mandate of training students with strong practical orientation since such tendency is highly probable.

\section{Conclusion}

The paper has explored the polytechnic systems and identified problems such as lack of a streamlined student industrial attachment model, lack of adequate facilities and lecturers with technology degrees in the systems. It has recommended ways by which industrial attachment can be streamlined to help complement students practical skills acquisition, and the use of the polytechnics as industry incubation centres to create industries that will give its graduate the distinctive practical skills from other analogous institution trained graduate in the job market for in terms of training and the creation of employment opportunities. For the polytechnic to realize their mandate as well as provide the middle-level management workforce for the country, it must equip and make the practical skills acquisition of its graduates paramount, so that graduates 
churned of from them are distinguished in practice due to the practical skills they imbued with. It is thus hoped that policy makers find the recommendations of this paper useful so that the training of polytechnic student is clearly demarcated from university student education in the areas of technical and vocational education.

\section{References}

Accra Polytechnic. (2012). Matriculation Brochure. Frontiers Publishing Ltd., Accra.

Ayogyam, A., Appienti, A. W., Jenkins, A. A. \& Abubakari, Z. (2012). The Impact of Students' Industrial Training on their Employability Status after Graduation: Evidence from Kumasi in Ghana. International Journal of Advances in Management and Economics, 1(4), 108-114

Ballinger, R. C. \& Lalwani, C. S. (2000). The role of internships in marine policy and integrated coastal management higher education. Ocean and Coastal Management, 43, 409-29.

Ghana Business News. (2013). Ghanaian polytechnics have completely lost focus. Retrieved on April 9, 2013 from < www.ghanabusiness.com>

NCTE. (2012). Norms for Tertiary Education in Ghana, Accra, Ghana.

Polytechnics Scheme of Service. (2009). Accra, Ghana

Ghana Legal. (2013). Ghana Laws: Polytechnic Law 1992 (PNDCL 321), Polytechnics Acts 745 of Ghana 2007. Retrieved on February 2013 from < http://ghana legal.com /?id=3\& law= 545 \&t= ghana-laws $>$.

Stuliff, K. (2000). Integrating academics and industry: A challenge for both sides. ACM J. Computer Documentation, 24(1), 33-8. 